\title{
A New Cross-Domain Strategy for Safeguarding the Danish Cultural Heritage
}

by NIELS MARK

\section{INTRODUCTION}

In the spring of 2003, the Danish Ministry of Culture launched a report, which comprised an evaluation of existing strategies for safeguarding the Danish cultural heritage and recommendations for future development. The report is very ambitious and covers all kinds of cultural material in archives, museums and libraries with a national responsibility. Two working committees with members primarily from the national institutions, each headed by the heads of the two departments in the ministry, were set up and given 8 months to produce the report (DMoC, 2003).

In this paper I shall shortly inform you of the background for the investigation, the procedures and analyses in the work process, the results, the most important recommendations and finally, the library sector's expectations to future development.

\section{BACKGROUND OF THE REPORT}

Like other national institutions with a responsibility for the cultural heritage, the national Danish institutions have always been greatly concerned about protecting their collections. Therefore, each institution presented the Ministry of Culture with the problems they had identified and with safeguarding plans, in some cases including rough financial estimates. Without being immoderate, I can safely state that the two libraries with national functions made the most careful analysis: The Royal Library and The State \& University Library. The Royal Library primarily focused on the printed material, whereas The State \& University Library - which hosts the national collection of Radio and TV, The Danish Sound Archive, including Danish music etc. - primarily focused on the audiovisual material. Several times, the libraries have joined forces to point out the necessity of collecting and preserving electronic material from the Internet.

Apart from addressing the Ministry of Culture, the libraries also tried to arouse political interest and understanding of the problem. In awareness of the political interest and an increasing pressure from the national cultural institutions the Ministry of Culture therefore asked the two libraries and the Danish National Library Authority to produce a preliminary report on the future protection of the digital cultural heritage. The conclusion in this report was unambiguous. It underlined that a great amount of important digital 
material had already been lost and that immediate action was needed to prevent further losses. Both the Ministry and some politicians were alarmed by the report, and a hearing in the Cultural Committee of the Danish parliament (Folketinget) was set up, focusing on the national cultural heritage in its totality.

The main problems concerning museums, archives and libraries were presented and discussed. The hearing was a veritable breakthrough and made the Cultural Committee ask the Cultural Ministry to account for the situation of the cultural heritage and to produce a cross-domain strategy including the following elements:

- a description of existing efforts

- an estimation of immediate and long-term needs and an evaluation of actual and long-term needs

- an account of alternative safeguarding strategies

- a prioritisation of safeguarding and conservation, following certain premises

- $\quad$ an evaluation of the suitability of existing conservation strategies, based on legislation and technological possibilities

- a thorough overview of financial consequences of the recommended strategies

- $\quad$ an evaluation of the possibilities for strengthening inter-institutional cooperation

It was decided to solve the task by establishing two working committees. The first was to examine the physical cultural heritage, whereas the second was to focus on the electronic heritage. The electronic heritage was in this respect defined as electronic material in the broadest sense, including analogue and audiovisual material.

The committee members were representatives from the main institutions within the archive, museum, and library sector. Each working committee was headed by one of the two heads of the two departments in the ministry. It was with great energy and enthusiasm we started the work. The ministry, too, found it very important because the national cultural institutions make up a substantial part of the ministry's responsibility. Besides, the ministry needed a tool to fulfil its obligations towards the institutions within the three sectors, so they saw the working committee's final report as a vital part of its decision-making.

My colleague, director of The Royal Library Erland Kolding Nielsen and I participated in each of our working committees. I participated in the "digital committee", and in the following account, I shall focus mainly on the working process and results within this particular area, only commenting briefly on the "physical committee work". 


\section{WORKING CONDITIONS AND PROBLEMS ENCOUNTERED IN THE COMMITTEE WORK}

Both working committees were asked to present different scenarios of future safeguarding strategies, but the Ministry of Culture demanded that at least one of the scenarios be financially neutral and feasible within the existing budget. This was, of course, not realistic but luckily, the final result has ensured more money to all the national institutions.

As a member of the "digital committee", I found the work process much more interesting than that of the physical committee. This was mainly due to an essential difference between the two working committees. The problems and solutions discussed in relation to the physical material differed greatly for archives, museums and libraries respectively, whereas the discussion of digital and audiovisual material was much more homogeneous. However, both working committees ended up presenting the ministry with interesting scenarios and valuable recommendations in the final report.

Before I present the main content of the final report, I will shortly comment on the premises and methods used in the analysis of the digital and audiovisual materials. The Ministry of Culture knew that the libraries had some experience in collecting and preserving digital material and decided to draw upon this experience. So, before the "digital committee" started its meetings, two specialists from the State \& University Library presented the members with a state-of-affairs report on worldwide handling of digital archiving. In addition, the library had collaborated with the Danish Broadcasting Corporation in producing a report on digitisation of radio- and TV archives. The two experts from my library continually supported the "digital committee" throughout the work process, which meant that the "library view" carried extra weight in the committee debates. During the whole process, there was an eminent cooperation with experts from The Royal Library. The background material was the above-mentioned state-of-affairs report, the report on digitisation of radio and $\mathrm{TV}$, and existing safeguarding plans with recommendations based on former experiences such as the change of the Depository Law in 1997. According to this law, non-printed material was partly included in deposit materials, whereas dynamic and interactive material from the Internet was not covered. Finally, the results of a pilot study on web archiving proved to be vital. This pilot study consisted of harvesting of all Internet material relating to the municipal elections of 2001. It proved the feasibility of the harvesting method, and it demonstrated that Internet harvesting could be realised at a reasonable price.

In March 2003, after approximately ten separate committee meetings and two joint meetings, the work was finished. Although there was some scepticism among the national institutions when we started, we ended up with final recommendations acceptable to all. Looking back, I think the reason that we could solve such a complex task regarding the digital and audiovisual heritage in a satisfactory manner is, first and 
foremost, the fact that we spent much time on defining and describing the elements included in digital and audiovisual archiving. Secondly, we kept a very tight time schedule.

\section{RECOMMENDATIONS OF THE REPORT}

To summarise the main recommendations of the final report, both working committees focused on collecting, safeguarding and accessing the cultural heritage, both committees recommended closer cross-sectorial cooperation, and finally, both committees recommended an adjustment of the existing legislation in some areas.

Regarding physical material, there was a specific recommendation to coordinate the efforts of the various museums, and a general recommendation to strengthen cooperation between all cultural heritage institutions with respect to registration methods.

As far as the challenge of preservation is concerned, the necessity of prioritising was underlined, and it was suggested that guidelines for preservation and conservation be produced. Regarding the library sector, it was recommended to produce guidelines and plans for developing facilities for mass deacidification of print material. However, from the point of view of the institutions, the most concrete result was doubtless a strong recommendation to establish appropriate storage facilities for archives, museums and libraries. Both the Royal Library and the State \& University Library have already benefited from this recommendation.

The digital committee covered areas such as film, radio/TV, analogue and digital audiovisual material, sound recordings, physical digital media such as CDs, CD-ROMs as well as DVDs, and last but not least - Internet material.

It was recommended that the principles introduced in the revised Legal Deposit Law from 1997 apply to all types of material. The most interesting point, however, was material collected from the Internet, for which a combination of three principles for harvesting the material was recommended:

- $\quad$ cross-section harvesting (snapshots/screen dumps) of Danish websites four times a year

- $\quad$ one extensive event-based harvesting a year (Danish)

- complete harvesting of eighty Danish Internet sites of special interest to the Danish public

The assumption of this strategy is that it is financially acceptable and that it will ensure a representative collection of relevant web information. 
The recommendations regarding radio/TV-production are very interesting too. It was suggested that all Danish radio- and TV broadcasts with nation-wide coverage be deposited in the State and University Library as a part of a new and revised edition of the existing Legal Deposit Law. Besides, it was recommended that material from local radio and TV channels only be collected in a representative amount twice a year.

This is a very visionary solution and as far as I know, it has not been included in international deposit laws before. Danish film productions are expected to be covered by this new law too. The report also recommended that in principle, all material collected as a part of the electronic and audiovisual heritage be registered. Regarding Internet material, it was recommended that metadata for each harvesting, e.g. time, volume, quality etc. be registered. However, there is also a financial alert involved: registration of the electronic material ought to be organized in accordance with cost-benefit considerations and primarily automatically.

The final report states that safeguarding of digital material will be possible if a wide range of suitable methods and strategies is chosen. However, it also underlines that both strategy and methods must be arranged in cooperation with international centres and institutions working with digital archives. In this respect, a Danish participation in the international research in the area is of vital importance.

Regarding safeguarding of film, audiovisual material and radio/TV-production, it has been recommended that all analogue material be digitised. Actually, different initiatives have already been initiated in this respect. As far as the most expensive productions are concerned, namely radio/TV broadcasts, the Danish Broadcasting Corporation has developed a digitalisation strategy, according to which the State \& University Library will receive copies.

Access to electronic material has been one of the key points in the discussion all along. The digital committee was of the opinion that material collected as a part of the cultural heritage should at least be accessible for personal studies, and consequently ended up with the following recommendations:

- Legal deposit material should at least be accessible at the deposit libraries.

- All research should be accessible to different kinds of electronic material through restricted online networks.

Specific Recommendations for Handling Internet Material:

- “Open access material” should continue to be accessible for personal studies from computers in both public and research libraries. 
- "Restricted access" material, to which access has hitherto been granted only in special cases, should only be accessible from terminals in the two deposit libraries.

Concerning radio/TV material the situation is more complicated. There are already certain agreements that allow use of specific programmes, for example news and current affairs news features, to which access is granted only through library computers, and the report recommends that it be kept that way. Furthermore, it is recommended that specific research access be granted to researchers who can document their field of research. In that case, they can access the material at the State \& University Library only.

\section{Organisational Consequences}

In spite of several recommendations in favour of a stronger cooperation between cultural institutions, there are no plans of changing existing institutional structures. The responsibilities of each institution have been defined in some areas, but a common steering body for museums, archives and libraries as known, for example, in Norway, was never discussed. It has, however, been recommended to establish a steering committee with representatives from the main institutions in order to safeguard the digital heritage. More interesting from the point of view of the libraries, however, is a recommendation that a web-archiving centre with shared responsibilities among the participating institutions be established. It is our hope that the Royal Library and the State \& University Library will be given joint responsibility for this part of the heritage.

\section{Financial Scenarios}

Each working committee presented three respectively four financial scenarios, of which one was cost neutral.

I will not go into detail about this, but just briefly mention the scenario concerning the digital parts. The digital committee was trying to be realistic and modest. Therefore, one of the main points in all three scenarios was a revision of the Legal Deposit Law, to ensure that all electronic material as well as radio/TV productions and films are covered. This will be possible to finance by retrenchments in other areas. The second scenario, which presupposes a budget of 20 million DKK a year (a little less than 3 million Euro), would ensure sufficient funds for retro-digitisation projects, financing of research activities, and further development. The third scenario was planned to cover some special developing costs for the archives and was not exactly calculated and consequently rather vague.

\section{Legal Consequences}

A very important recommendation from the working committees was a revision of the existing Legal Deposit Law and The Copyright Act, including the following major changes: The paragraphs relating to legal deposit should be deleted from The Film Law 
and The Radio and TV Law. The deleted parts should be incorporated in the revised Legal Deposit Law instead.

Regarding deposit material, the report explicitly stated that the material covered by the Legal Deposit Law should be published works of Danish origin or published works relating to Denmark, in other words, so-called Danica, which comprises material

- $\quad$ made by Danes, or

- concerning Denmark, or

- $\quad$ in Danish, or

- $\quad$ performed by Danish artists

The idea behind defining Danica as broadly as above was to ensure that the revised Legal Deposit Law would cover all published material worthwhile preserving as a part of the Danish cultural heritage. As mentioned above the recommendations also applied to Internet and radio/TV broadcasts. This means that the traditional delivery of deposit material would be replaced by centralised collecting when possible.

\section{The Impact}

There is no doubt about the value of the final report and its recommendations. The work was initiated by the cultural committees of the Danish parliament (Folketinget), which increases its credibility. It has thus ensured an increased focus on the cultural heritage, unveiled problems and the necessity of investments in that area, and will consequently improve the financial basis for future safeguarding tasks. In addition, it will strengthen the cooperation, not only between the three cultural sectors, but also between the cultural institutions and the research and educational sector, to which the majority of users belong. So if the recommendations in the report are fulfilled, it means a great step forward in favour of safeguarding the cultural heritage.

\section{ONE YEAR LATER}

To start with the physical part of the cultural heritage, not all recommendations have been met yet, but all the major national cultural institutions, including the Royal Library and the State \& University Library, have now been ensured sufficient funds to extend their storage facilities. This will give these institutions a solution to a very urgent problem, but even more interesting for the two libraries is the fact that The Ministry of Culture has asked the two libraries to present a draft for this law with an estimate of its financial consequences. The draft has been presented to the Ministry of Culture and a 
new law will probably pass the Danish parliament next year. It is expected that all recommendations in the report will be fulfilled then. It is also expected that the abovementioned web-archiving centre with responsibility for Internet material will be a virtual centre run in cooperation between the two libraries, so that The Royal Library will be responsible for cross-section harvesting whereas the State \& University Library will be responsible for event-based harvesting and harvesting of sites of special interest.

Unfortunately, there is still some uncertainty as regards access to the digital cultural heritage. The recommendations concerning restricted research access will probably be fulfilled, but we still do not know to which extent access will be granted to the public. We hope, however, that upcoming negotiations with different rights holding organizations and a revision of the Copyright Law will result in an acceptable outcome.

In conclusion, one year after the report was published, we are still very optimistic. The increased political focus on the national cultural heritage and a greater emphasis on a cross-domain strategy have meant a progress in all areas and a better understanding of the necessity of financial support to ensure future safeguarding activities.

\section{REFERENCES}

DMoC - Danish Ministry of Culture: Udredning om bevaring af kulturarven, Copenhagen 2003.

www.kum.dk/graphics/kum/downloads/Publikationer/Bevaring_af_Kulturarven.pdf

\section{WEB SITES REFERRED TO IN THE TEXT}

The Danish National Library Authority. http://www.bs.dk/english.ihtml

The Royal Library. http://www.kb.dk/index-en.htm

The State and University Library. http://www.statsbiblioteket.dk/engelsk/welcome.htm 